Journal of Qualitative Criminal Justice \& Criminology • Pre-Issue Pubs

\title{
Editor's Introduction to \\ Comments on the Crimcon \\ Controversey
}

Scott Jacques

Published on: Jun 22, 2021

DOI: $10.21428 / 88 d e 04 a 1.7 f 59337 f$

License: Creative Commons Attribution 4.0 International License (CC-BY 4.0). 
This piece introduces two comments and a rejoinder on the "CrimCon Controversy." I learned of the controversy on Twitter, in early January 2021. Based on tweets, I gathered the controversy has two parts:

- Reinhard, Stafford, and Payne (2021) covertly observed the inaugural conference of the Criminology Consortium (CrimCon) and published their findings. People labeled their research as unethical and their article as offensive.

- Two CrimCon board members, Antunes and Boppre (2021), learned that their coboard member, Payne, is part of the above study. The cascading effect was their resignation from the board and CrimCon's implosion, since rebuilt.

This controversy is important and interesting for a few reasons: it concerns the right and wrong ways to do research, interpret and discuss results, and lead or leave an organization. As an advocate for open access, moreover, I was saddened that "this" happened with an innovative free conference. To open criminology, all of us need organizations like CrimCon, and initiatives like their conference, to grow in number and strength.

So in a tweet, in my capacity as editor of QC, I made a call for comments on "the @CrimConOrg controversy ... Take a reasoned position in 1000-2000 words. Pub

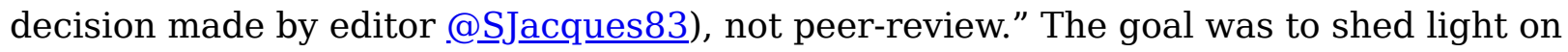
what happened, not arbitrate, with the hope that would help us to avoid repeating the past.

That call led to two comments: Buckler and O'Neal's (2021) The CrimCon Controversy: An Essay_Addressing IRB Approval, Informed Consent, and the Interpretation of Results; and, Antunes and Boppre's (2021) A Test of Leadership: Insight from Two Women from the Founding_CrimCon Board. They mostly address, respectively, the first and second parts of the controversy. Also, we received a sort of rejoinder from CrimCon's new board; see Ticknor et al.'s (2021) Seeing the Vision and Moving Forward: The Future of the Crimcon Conference From the New Board.

I agree with some of the authors' arguments, which is to say I disagree with some too. You should decide for yourself, with an open mind. Whoever's side we land on (see Becker 1967), we should be empathetic to all.

Per my tweet, everyone was welcome to submit a comment. I emailed a personal invitation to "the accused": the investigator-authors plus CrimCon's original president, 
Wilczak. Understandably, they declined my invitation. That choice should not be interpreted as an admission of guilt. I do wish they had written something for us, and the invitation is standing.

\section{References}

Antunes, J., \& Boppre, B. (2021). A Test of Leadership: Insight from Two Women from the Founding CrimCon Board. Journal of Qualitative Criminal Justice \& Criminology, this issue.

Becker, H. S. (1967). Whose Side Are We On? Social Problems, 14, 239-247.

Buckler, K., \& O’Neal, E. (2021). The CrimCon Controversy: An Essay Addressing IRB Approval, Informed Consent, and the Interpretation of Results. Journal of Qualitative Criminal Justice \& Criminology, this issue.

Reinhard, D., Stafford, M. C. \& Payne, T. C. (2021). COVID-19 and academia: Considering the future of academic conferencing. Journal of Criminal Justice Education. https://doi.org/10.1080/10511253.2020.1871047

Ticknor, B., Warner, J., Rojas, C., Madero, A., \& Lytle, D. (2021). Seeing the Vision and Moving Forward: The Future of the CrimCon Conference From the New Board. Journal of Qualitative Criminal Justice \& Criminology, this issue. 